\title{
EXTENSÃO DO SABER NUMA UNIVERSIDADE AMAZÔNICA ${ }^{1}$
}

Fernando Arthur de Freitas Neves

Universidade Federal do Pará fafn@ufpa.br

Durbens Martins Nascimento Universidade Federal do Pará proex.dpp@gmail.com

\section{Resumo}

Descortinar as muitas possibilidades da intervenção extensionista da UFPA, pela articulação da exposição pública do saber institucionalizado, mobilizando o portfólio de técnicas, serviços, instrumentos e tecnologias tornou-se um modo de operar da política de gestão de extensão. Esta ação privilegia a ampliação da legitimação social da universidade enquanto apura e coopera com o saber existente nos territórios contíguos a universidade.

Palavras-chaves: Extensão. Utopia. Institucionalização. Relação e Saber. Gestão Política.

\section{EXTENSION OF KNOWLEDGE IN AN AMAZON UNIVERSITY ${ }^{2}$}

\begin{abstract}
Seeking the many possibilities of intervention extensionist UFPA, the articulation of public show of the institutional knowledge, mobilizing the portfolio of technical services, tools and technologies has become a mode of operation of the management policy of extension. This action favors the expansion of social legitimization of the university as judges and cooperates with the knowledge existing in the territories adjoining the university.
\end{abstract}

Keywords: Extension. Utopia. Institutionalization. Relationship and Knowledge. Policy Management.

\footnotetext{
${ }^{1}$ Os autores agradecem a contribuição da bolsista do Programa Conexões do Saber, Charlene de Carvalho Silva, estudante do Curso de Estatística da UFPA, que agrupou os dados e confeccionou as Tabelas e Figuras do presente texto.

${ }^{2}$ Os autores agradecem a contribuição da bolsista do Programa Conexões do Saber, Charlene de Carvalho Silva, estudante do Curso de Estatística da UFPA, que agrupou os dados e confeccionou as Tabelas e Figuras do presente texto.
} 
Extensão do saber numa universidade amazônica

A universidade no século XXI será certamente menos hegemônica, mas não menos necessária que foi nos séculos anteriores. A sua especificidade enquanto bem público reside em ser ela a instituição que liga o presente ao médio e longo prazo pelos conhecimentos e pela formação que produz e pelo espaço público privilegiado de discussão aberta e crítica que constitui.

Boaventura dos Santos

\section{INTRODUÇÃO}

Este artigo, inspirado nas palavras de Boaventura dos Santos na epígrafe, tem a pretensão de apresentar algumas reflexões sobre a dimensão da extensão do saber universitário na UFPA para este milênio a partir da ótica de uma nova gestão universitária inaugurada neste ano de 2010 na UFPA. A ressalva do ano não desmerece os esforços e a contribuição de geração de gestores do passado que abnegadamente ajudaram a transformar a UFPA numa das maiores IFES do Brasil. Destaca-se apenas a necessidade de examinar os contornos que adquire a extensão em contexto de desenvolvimento e implementação de políticas educacionais no ensino superior.

As ideias, proposições e hipóteses aqui levantadas, e para serem testadas ao longo da década, são menos produto de achado de pesquisa científica do que baseadas na experiência acadêmica e profissional de seus autores como pesquisadores e, sobretudo, como dirigentes Pró-Reitoria de Extensão da UFPA. Essa conclusão, entretanto, não minimaliza essas ideias e proposições, mas recoloca na ordem do dia a necessidade de pensar a Universidade e uma de suas dimensões, a extensão, sob o prisma da interdisciplinaridade e da percepção da gestão compartilhada e democrática enquanto exigência para encarar os desafios acadêmicocientíficos que a modernidade requer principalmente no encontro com a cidadania como atesta este I Seminário de Projetos Educacionais e a Construção de uma Nova Cultura Acadêmica.

\section{A EXTENSÃO AO ENCONTRO DAS UTOPIAS}

A UFPA neste milênio tem desafios a enfrentar em todas as suas dimensões, especialmente na extensão universitária. Estes novos desafios decorrem da necessidade de adequar-se aos preceitos institucionais globais que residem nas mudanças vivenciadas nas últimas duas décadas no mundo. Essa realidade tem peculiaridades ambientais, sociais e econômicas inerentes a região na qual se busca atingir metas que modifiquem o passivo histórico de um espaço social marcado territorialmente e socialmente pelas distâncias sociais, ambientais e econômicas. 
Extensão do saber numa universidade amazônica

Utilizando-se de mecanismos de gestão modernos disponíveis para dar suporte ao modelo de organização da universidade baseado na competência científica, no desenvolvimento do ensino, da pesquisa e da extensão. Mecanismos como a integração sistêmica entre as diversas organizações através da informatização, permitem melhorar a qualidade e relevância do trabalho acadêmico. A PROEX, na parte que lhe cabe, ao socializar o conhecimento com a comunidade interna e externa à universidade, exemplificado no caso da consagrada Jornada de Extensão que caminha para a sua $13^{\mathrm{a}}$ edição, põe em prática uma visão estratégica por meio do compartilhamento das informações e ideias extraídas da pesquisa e do ensino e retrabalhadas no processo de inserção social com setores mais vulneráveis da sociedade. Com esse procedimento a PROEX almeja contribuir com a diminuição do hiato da desigualdade social e regional. A universidade tem que incentivar os seus corpos docente, discente e técnico-científico para sugerirem atividades a serem desenvolvidas a partir de sua missão, sempre guiada pelo princípio da respostas satisfatórias as exigências impostas pelos cidadãos.

Dentre as políticas cuja implementação tem alterado a passagem da UFPA, dar-se ênfase ao Programa de Reestruturação e Expansão das Universidades Federais - REUNI que estabelece em seu Art. $1^{\circ} \S 1^{\circ}$ a meta global de crescimento gradual da taxa de conclusão média dos cursos de graduação presenciais para $90 \%$ e da relação de alunos de graduação em cursos presenciais por docente para $18 \%$, no prazo de 5 anos, tendo como base o ano de 2007 . É um desses programas federais cuja efetividade criam as condições político-pedagógicas para a afirmação de ações de melhoria da oferta de seus cursos e contribuem para a formação/capacitação dos alunos.

Os desafios da UFPA que aderiu ao programa aparentam não serem poucos, uma vez que ela é uma instituição multicampi, ou seja, uma instituição de ensino superior composta por diversos campi articulados solidária e cooperativamente, uma espécie de universidaderede numa referência ao território-rede e ao Estado-rede de Rogério Haesbaert (2004). Esse formato de organização impõe um desafio a mais que é fazer com que os gestores de suas unidades acadêmico-administrativas e de suas subunidades acadêmicas na Sede e nos campi, desenvolvam suas atividades de forma harmônica para que efetivamente atinjam as metas com as quais a instituição se comprometeu ao aderir ao REUNI.

A PROEX neste contexto tem buscado efetivar uma política de desenvolvimento das atividades na sua área de abrangência institucional e na convergência proativa tem se valido de instrumentos de gestão informacionais que ajudem a acompanhar a vida do estudante universitário na esperança de evitar a evasão e a retenção dos alunos da graduação. $\mathrm{O}$ 
conjunto de bolsa fornecida pela PROEX em especial a Bolsa Permanência, como atesta a Figura abaixo, demonstra que estamos ajudando na fixação do estudante na Universidade, e ao fazer isso ambiciona atingir as metas estabelecidas pelo programa REUNI.

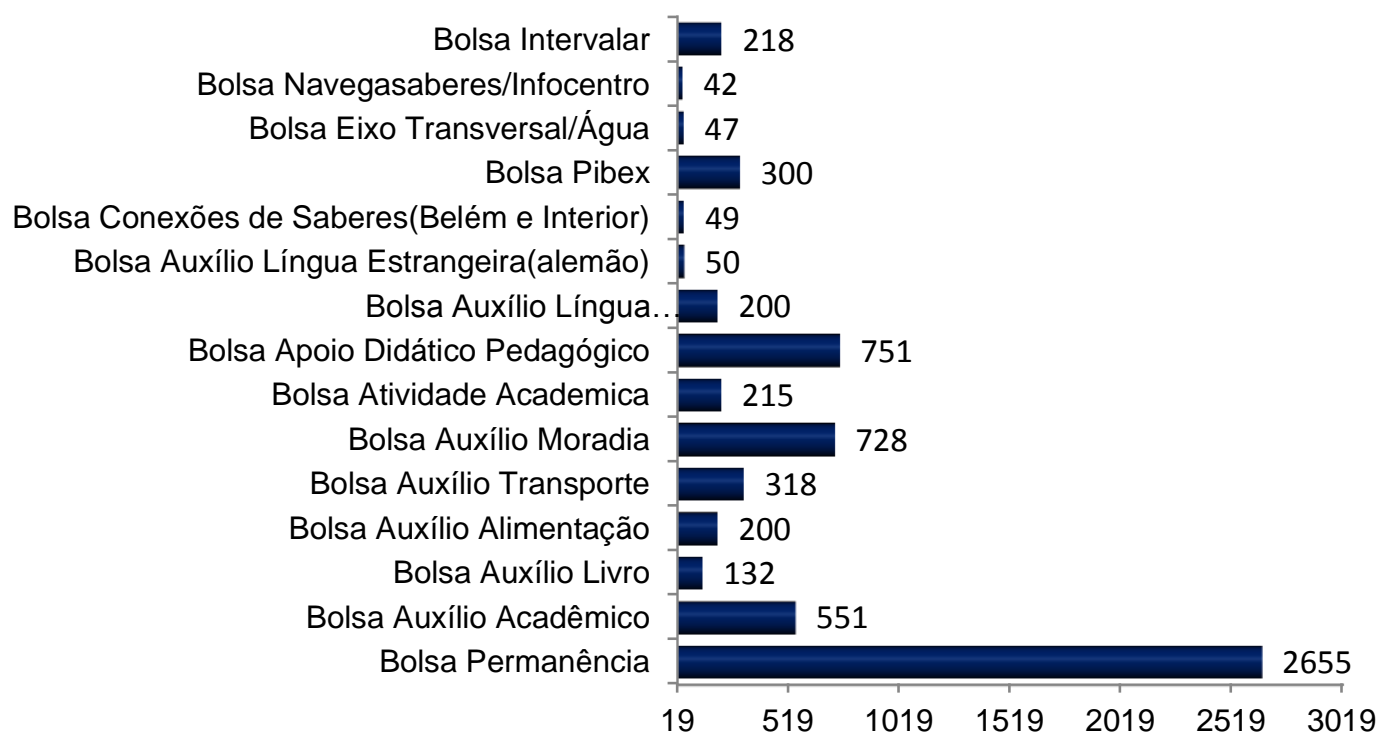

Figura 1 - Quantidade de auxílio concedido no ano de 2009 e 2010 -UFPA/PROEX

Fonte: Diretoria de Assistência e Integração Estudantil e Diretoria de Projetos/PROEX/UFPA/2010

Os dados apresentados na Tabela 1.0 e representados também na Figura 2.0 nos dão uma ideia objetiva da dinâmica das pessoas beneficiadas por programas e projetos de extensão, seja na forma de atendimento assistencial, seja por meio da educação continuada ou, por fim, no envolvimento de comunidades, vivendo em espaços sociais carentes de equipamentos urbanos, em processos de organização social na capacitação de jovens e adultos ou de divulgação de conhecimentos inovadores mediante instrumentos de divulgação científica e cultural que dispõe as diversas mídias na contemporaneidade. Das 177.626 pessoas atendidas ao longo de 2008, esse número saltou vertiginosamente para $606.301 \mathrm{em}$ 2009.

\begin{tabular}{lcccc}
\hline \hline & \multicolumn{3}{c}{ Programas e Projetos } \\
\cline { 2 - 5 } Áreas Temáticas & \multicolumn{2}{c}{2008} & \multicolumn{2}{c}{2009} \\
\cline { 2 - 5 } & \multicolumn{2}{c}{ Beneficiados } & \multicolumn{1}{c}{ Beneficiados } \\
\hline \hline Comunicação & 32750 & 800 & 1485 & 2264 \\
Cultura & 13681 & 29304 & 6720 & 48772 \\
Direitos Humanos & 4676 & 9766 & 28810 & 22320 \\
Educação & 10851 & 25564 & 53438 & 143066 \\
Meio Ambiente & 3297 & 5488 & 11441 & 46634 \\
Saúde & 3513 & 33364 & 26025 & 183361
\end{tabular}


Extensão do saber numa universidade amazônica

\begin{tabular}{lcccc} 
Tecnologia e & 70 & 3974 & 9321 & 21890 \\
Produção & & & & \\
Trabalho & 84 & 444 & 754 & 0 \\
Total Geral & 68922 & 108704 & 137994 & 468307 \\
\hline
\end{tabular}

Tabela 1 - Número de pessoas beneficiadas por programas e projetos segundo a temática no ano de $2008 \mathrm{e}$ 2009 UFPA/PROEX

Fonte:DPP/PROEX/UFPA/2010

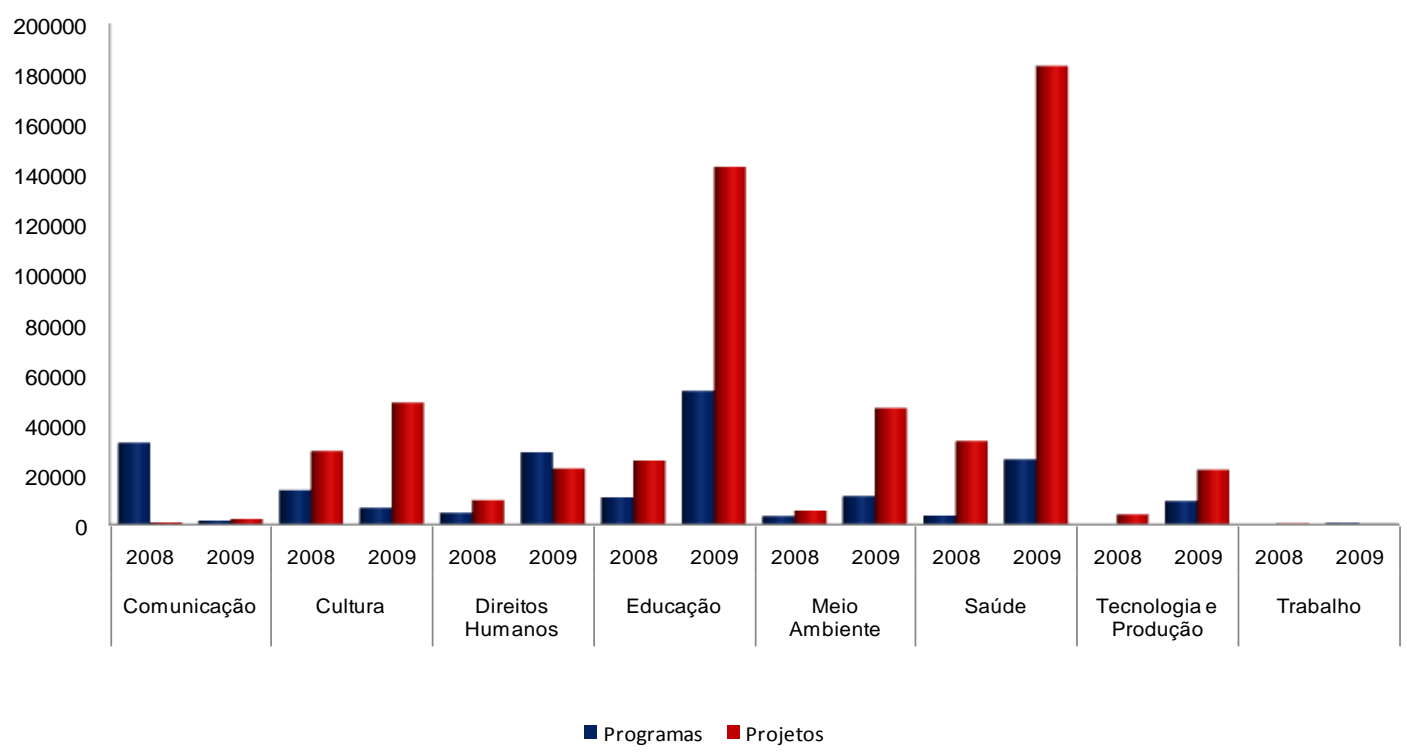

Figura 2 - Número de pessoas beneficiadas por programas e projetos segundo a temática no ano de 2008 e 2009 UFPA/PROEX

Fonte:DPP/PROEX/UFPA/2010

À primeira vista, o número obtido em 2009, em comparação com o ano anterior representa um avanço extraordinário na inserção social da extensão universitária na sociedade local e regional. Contudo, é preciso notar que essa expansão não ocorreu de forma sincronizada em todas as áreas da extensão. Os dados revelam que houve uma queda de 2008 a 2009 no número de pessoas atendidas entre programas e projetos agrupados na categoria Comunicação, em contraste com o crescimento das áreas das outras áreas, isto é, Saúde, Educação, Cultura, Trabalho, Meio Ambiente, Tecnologia e Produção e Direitos Humanos.

Esse resultado instiga os gestores da PROEX o desafio de investigar em profundidade as razões pelas quais as outras áreas, isto é, Tecnologia e Produção e Trabalho não se expandiram no mesmo ritmo que as demais. È digno de nota, a rápida ampliação da área de Meio Ambiente. Neste caso, uma avaliação superficial permite-nos aferir que se trata de uma área que cresce em todos os setores das universidades, assim como na sociedade suas influências em virtude dos desdobramentos da crise ambiente no presente quadro histórico.

Por outro lado, quando se usa o indicador de número de programas e projetos por Unidade Acadêmica para os anos de 2008 e 2009, a comparação como visualizadas na Tabela 2.0 e na Figura 3.0, a relação entre o aumento de pessoas beneficiadas no ano de 2009, 
Extensão do saber numa universidade amazônica

conforme visto acima, e o incremento ascendente em algumas áreas da extensão não significou o aumento na mesma proporção da quantidade de programas e projetos nestas respectivas áreas. Ou seja, cresceu o número de atendidos, mas não o de programas e projetos na extensão. Em suma: nas áreas de Comunicação, Cultura, Direitos Humanos, Tecnologia e Produção e Trabalho houve uma queda no número de programas e projetos, apesar de ter tido um aumento o número de pessoas envolvidas nas atividades.

\begin{tabular}{lcccc}
\hline \hline & \multicolumn{4}{c}{ Programas e Projetos } \\
\cline { 2 - 5 } Áreas Temáticas & \multicolumn{2}{c}{2008} & \multicolumn{2}{c}{2009} \\
\cline { 2 - 5 } & 1 & 7 & 1 & 4 \\
\hline \hline Comunticação & 5 & 28 & 7 & 18 \\
Cultura & 7 & 6 & 8 & 3 \\
Direitos Humanos & 22 & 54 & 22 & 58 \\
Educação & 3 & 11 & 4 & 17 \\
Meio Ambiente & 12 & 51 & 17 & 60 \\
Saúde & 1 & 15 & 2 & 5 \\
Tecnologia e & & & & \\
Produção & 1 & 4 & 2 & 0 \\
Trabalho & 51 & 176 & 63 & 165 \\
Total Geral &
\end{tabular}

Tabela $2 \overline{\overline{-} \text { - Quantidade de programas e projetos por área temática no ano de } 2008 \text { e } 2009 \text { UFPA }} /$ PROEX Fonte:DPP/PROEX/UFPA/2010

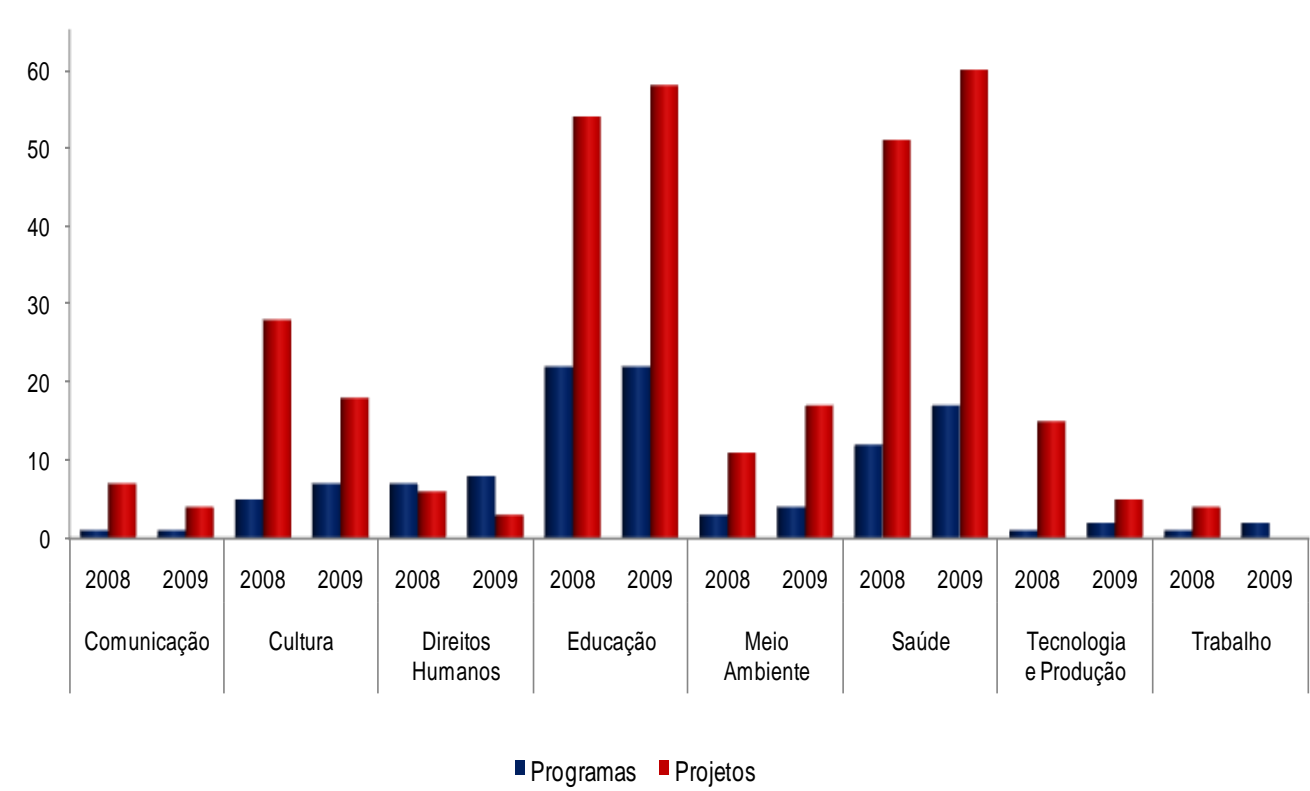

Figura 3 - Quantidade de programas e projetos por área temática no ano de 2008 e 2009 UFPA/PROEX Fonte:DPP/PROEX/UFPA/2010

Quando se analisa a distribuição espacial do programas e projetos pelos campi para o 
ano de 2008 e 2009, Figura 4.0, verifica-se claramente a concentração deles no campus de Altamira. Mas quando se compara a relação de projetos e programas com o número de docentes nos campi, chama a atenção a assimetria entre docentes e projetos e programas. Ou seja, é preciso avaliar os motivos pelos quais em algumas Unidades Acadêmicas, bem como alguns campi e núcleos há um número significativo de professores que não se engajam na extensão.

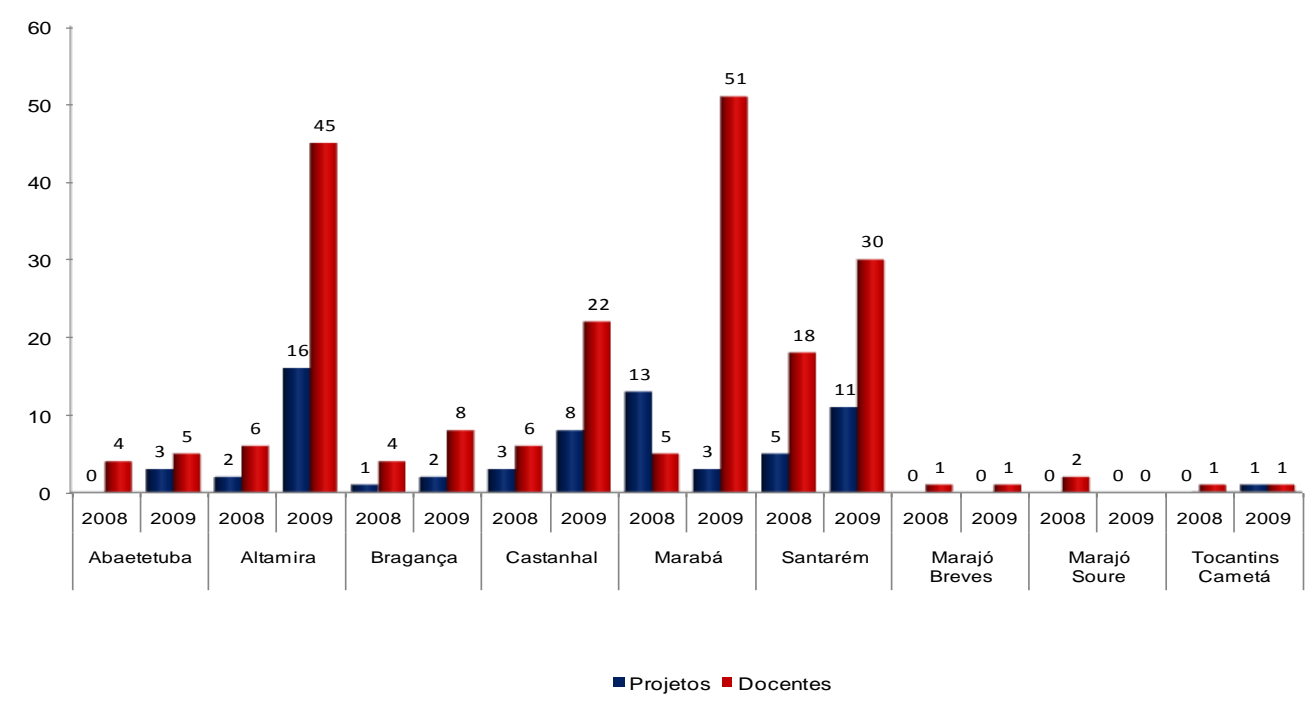

Figura 4 - Quantidade de projetos e docentes por campi no ano de 2008 a 2009 -UFPA/PROEX Fonte:DPP/PROEX/UFPA/2010

Por outro lado, a análise dos dados apresentados nas tabelas e figuras permite uma questão importante: esse movimento representa de fato uma intensificação na extensão com a melhora na qualidade da intervenção da UFPA? Esses dados revelam que a estratégia de ampliar os programas (principalmente) em detrimento do aumento do número é a melhor saída para o aprofundamento da relação com a sociedade? Sem dúvida, as respostas exigem uma tomada de decisão por parte os gestores da PROEX estimulando o envolvimento da comunidade universitária na extensão, a fim de avançar numa resposta mais plausível que se traduza em políticas de extensão mais eficiente na intensidade e expansão.

A PROEX vem despertando a atenção da comunidade universitária na medida em que desloca o enfoque da extensão para a parceria e atuação compartilhada com outras próreitorias a exemplo da PROPESP ${ }^{3}$ e da $\mathrm{PROEG}^{4}$ coma finalidade de fortalecer um arcabouço

${ }^{3}$ PROPESP e PROEX lançaram em 2009 o primeiro Edital Bolsa de Iniciação Científica Ação Afirmativa. Ofertando 50 bolsas ( 25 com fundos do CNPq e 25 com os recursos da Assistência Estudantil geridos pela PROEX/DAIE) para os alunos de graduação da UFPA, amplia-se a oportunidade para que jovens com trajetória acadêmica esmerada e em situação de fragilidade econômica possam ser mais qualificados e efetivamente possam dispor de mais um instrumento para democratizar o acesso ao fazer da pesquisa e às redes de C\&T. Em 
institucional para a implementação de políticas internas de acompanhamento da vida estudantil e de assistência fundamentalmente a seus alunos.

\section{A EXTENSÃO NA UFPA: DESAFIOS INSTITUCIONAIS E POLÍTICOS}

A extensão é uma característica da UFPA ao lado de outras instituições de pesquisa, contudo o signo da extensão como elemento constituinte ao ensino tornou-se uma condição da universidade brasileira estatuída pela experiência da cultura do Movimento Estudantil, posteriormente assimilada pela ditadura militar, finalmente consagrado na constituição brasileira em seu artigo $207^{5}$.

Há muitas formas de intervenção extensionistas descritas como palestras, conferências, cursos, oficinas, assessorias, comunicações, performances, apresentações em um portfólio bastante vasto das antigas faculdades até os dias presentes dos Institutos, Clínicas, Hospitais, Laboratórios, Observatórios, Núcleos e Agências. De saudosa memória o Centro Rural Universitário de Ação Comunitária (CRUTAC) ${ }^{6}$, caracterizado como um projeto de assistência universitária decretado pelos militares em consonância com o Projeto Rondon; imagem profética da imersão da juventude universitária no sertão do Brasil, na perspectiva de render o que restou da sociedade civil depois do golpe de 1964 à adesão ao programa de mega potência e integração da região amazônica à dinâmica do capitalismo conservador em via de modernização.

\footnotetext{
2010 será lançado o mesmo edital, a contribuição da PROEX será aumentada em 100\%, passando a ofertar mais 25 bolsas, totalizando 50 bolsas de Iniciação Científica Ação Afirmativa. Obviamente esta tomada de decisão espera atrair as agências de fomento a aumentarem o financiamento de Programas de Ação Afirmativa.

${ }^{4}$ Semelhante compartilhamento está em curso para oferta de 40 bolsas para o ensino, o formato de monitoria ou bolsa propriamente ainda precisa ser refinado sobre o plano de trabalho a cargo da PROEG, secundado pela PROEX. Os recursos da Assistência Estudantil geridos pela PROEX/DAIE têm sido mobilizados para suportar estas iniciativas. Maior convergência das pró-reitorias sinaliza a efetivação da indissociabilidade de ensino, pesquisa e extensão.

${ }^{5}$ Art. 207 - As universidades gozam de autonomia didático-científica, administrativa e de gestão financeira e patrimonial, e obedecerão ao princípio de indissociabilidade entre ensino, pesquisa e extensão. http://www.planalto.gov.br/ccivil_03/constituicao/constitui\%C3\%A7ao.htm. Acesso em: 27/05/2010, 19:35.

${ }^{6}$ Sem aprofundar o estudo sobre a importância do CRUTAC/UFPA, esta presença deixou algumas pistas da intervenção extensionista da UFPA como assinala COELHO, M. S. C.; DIAS, Ana Lucia B; SANTOS, Fábio A S. A Política de Interiorização da Universidade Federal do Pará no município de Cametá- Pa. Olhar de Professor (UEPG), Ponta Grossa- Paraná, p. 35-47, 2004. Este artigo pretendeu abordar a interiorização do ensino da UFPA, mas como é de conhecimento daqueles mais antigos, o Programa de Interiorização ficou a cargo da PROEX até bem recentemente. Não estou advogando em hipótese alguma o retorno a esta esquadra.
} 
Extensão do saber numa universidade amazônica

O I Plano de Desenvolvimento da Amazônia de 1974 descreve a ossatura dessa aventura e o eixo das reformas. Obviamente houve mediações, o contato permitia uma reflexão sobre as condições da promoção de assistência daqueles desassistidos, gerando algum inconformismo e atraindo voluntários para mitigar àquela situação.

A experiência daqueles envolvidos não chegou a despertar a paixão de Che Guevara narrada em suas Notas de Viajem ${ }^{7}$, mas criou uma perspectiva de intervenção sobre a realidade. Seria necessária uma revisão dos postulados do ensino superior público para que fosse alcançado o desenho corrente da extensão como a conversão do lócus de conhecimento como a capilarização da universidade prestando serviço, assistindo aos órgãos de gestão pública, auxiliando a confecção de estratégias de produção e circulação de mercadorias e serviços, gestando processos e produtos, partilhando a sorte de empreendimentos e sistema de cooperação, desenvolvendo e experimentando linguagens e sistemas para a sociedade.

Esta inovação pode ser percebida quando é instalado o debate sobre o caráter assistencialista dos programas, projetos, cursos, eventos e serviços cujo fim era tão somente diminuir as condições de pobreza sem criar uma reflexão sobre o sentido deste agir da universidade, de tal sorte a imprimir a difusão, aplicação e crítica sobre as políticas empregadas pelo estado ou por agentes privados; bem como constituir uma práxis acadêmica aonde ensino e pesquisa convertem-se em campo de intervenção para testar o conhecimento gerado na expectativa de estreitar os laços com a sociedade, constituindo um processo amplificando de formação acadêmica e cidadã nos membros da comunidade universitária contribuindo para a formalização da gestão, criação e realização do saber incorporado no quotidiano da sociedade. Esta dimensão aparece em linhas gerais no PDI 2001/2010 da UFPA que ainda orienta nossas atividades.

As assimetrias ainda são muito grandes entre as unidades da UFPA no que tange à extensão, ela sequer é corrente em toda instituição, apesar da imposição dos $10 \%$ de atividade obrigatória no plano político acadêmico de todos os cursos ser mais uma meta do que uma prática propriamente, serve de estimulo as mesmas unidades.

Em consonância ou não com a Pró-Reitoria, a procurarem configurar um campo de intervenção, traduzindo o processo educativo, cultural e científico em aporte às relações entre produção e reflexão do conhecimento com as demandas do desenvolvimento humano, social, ambiental e econômico.

\footnotetext{
${ }^{7}$ Walter Sales nos apresentou o filme Diário da Motocicleta com as anotações de Ernesto "Che" Guevara de La Serna e Alberto Granado (Con el Che por America), quando dois estudantes da área de saúde na década de 1950 percorrem a América do Sul numa motocicleta Norton 500, chamada de La Poderosa.
} 
Extensão do saber numa universidade amazônica

Temos muito a caminhar. Não há ainda uma sistematização significativa da produção de saberes tradicionais, aqui, novamente replicam-se assimetrias oriundas das tradições cientificas e artísticas distintas. $\mathrm{O}$ aprendizado da universidade com os saberes diversos nos desafia a conferir outro patamar de interação entre universidade e sociedade, mas há já instalado um consenso quanto à relevância de legitimar nossas ações junto à sociedade.

Dentre esses parâmetros a PROEX está organizada para superar os seguintes desafios: a indissociabilidade entre ensino, pesquisa e extensão; a integração pesquisa e pósgraduação com a extensão; implantação do fórum de extensão; fortalecimento de programas que viabilizem a cultura extensionista na educação básica; a inclusão digital; assegurar a diminuição da retenção e reprovação através da consolidação da assistência estudantil multicampi atentando para as situações de cotistas, etnias e vulnerabilidade econômico-psicosocial; criação de um fundo de financiamento das atividades de extensão; implantação das plataformas de cultura, de esporte e lazer e de extensão.

Este leque ganha maior credenciamento quando reconhecido nas ações elaboradas quanto à pertinência, atualidade e comprometimento social, em uma continua espiral de legitimação da sociedade com a universidade. Sem jamais criar a pretensão de substitui o estado ou a própria sociedade civil. A extensão da universidade compromete seu desenvolvimento com a oferta de trabalho intelectual, científico e artístico para serem apropriados nas experiências promovidas em diferentes modelos, projetos e programas que estimulem à emancipação dos grupos sociais, permitindo a universidade dedicar seu esforço para outras necessidades. Investir na articulação de espaços e canais permanentes com as esferas acadêmicas, governamental, e nas redes das organizações sociais da sociedade civil para o planejamento das ações extensionistas contando com a participação desses atores na confecção da agenda da PROEX; este posicionamento visa gradualmente estatuir a cultura de interação da Extensão com o Ensino e a Pesquisa, de longe o maior desafio no plano de desenvolvimento institucional. 
Extensão do saber numa universidade amazônica

Se a direção da PROEX apresenta essa concepção para a universidade, outros atores precisam ter conhecimento dessas diretrizes e com eles pactuar um plano de ação. A esse respeito é relevante mencionar o Edital Navega Saberes, lançado pela PROEX, ao colocar em evidencia a parceria da universidade e a gestão do estado do Pará, usando os Infocentros instalados pelo Programa Navevapará. Nossa expectativa é de potencializar a ação extensionista com a esfera digital na trasladação da produção de saber, nas mais diversas $\begin{array}{llllll}\text { formas } & \text { da } & \text { universidade } & \text { conhecimento, }\end{array}$ interiorizado pela população frequentadora destes Infocentros.

Esta é uma frente de atuação que mobiliza o dia a dia da PROEX, pois permite estreitar a Universidade Pública engajada na produção científica e socialização do conhecimento na sociedade paraense e amazônica. Com efeito, a UFPA não basta a si mesmo, é preciso construir regularmente mecanismos de ausculta mais eficazes para captar as demandas crescentes. Remediaremos esta situação com Fórum de Consultas da Sociedade Civil em 2010.

Ao retratar as ações de extensão apenas com a quantidade de programas e projetos não tornam evidente o significado de suas experiências, seria necessário a elaboração de outra metodologia para mensurar o impacto produzido na ação. A recusa em deixar clara a quantidade de pessoas atingidas na intervenção extensionista revela o descompasso com importância da avaliação político-técnica do procedimento, controle ou outro ensaio em execução.

No relatório de 2009, a exemplo de seus predecessores, procurou-se destacar os projetos, as experiências e o conhecimento do já feito, permitindo que a atividade de extensão ganhe a expressão de importância que a caracteriza neste momento histórico da universidade na região. A partir de julho de 2009 imprimimos uma contribuição ao fazer extensionista ao carrear os recursos para um núcleo de discussão a privilegiar os editais como forma de controle público e significação para experiência acadêmica inovadora da interdisciplinaridade, multidisciplinaridade e transdisciplinaridade, colocando o foco no problema ao invés da abordagem centrada na circunscrição disciplinar.

O Edital Temático Água evidencia o exercício em atrair a instituição para sintetizar as conexões dos campos disciplinares diante de uma questão estratégica para desenvolvimento humano, em particular pela nossa condição de habitarmos a confluência das bacias do Amazonas e do Tocantins, além do aquífero Altér do Chão, recém-descoberto, acentuando a responsabilidade da UFPA com esta temática. 
Extensão do saber numa universidade amazônica

Os horizontes se deslocam, o equilíbrio de mira refeito quer alcançar à realização do saber mobilizando a inovação em paralelo com a incorporação das proposições do saber tradicional. Momento este de teste das mudanças na estrutura institucional, no estabelecimento de metas a serem figuradas no novo PDI e na afirmação de seu princípio multicampi; o que atribui a esta universidade a necessidade de edificar uma efetiva política de extensão sem incorrer no equivoco de tentar substituir o estado (união, estado e município) na missão de consolidação, formulação e execução de políticas públicas que levem a um processo de transformação de nossa realidade social, no sentido de torná-la apta para oferecer tecnologias e crítica para sociedade. Agente partícipe é nossa condição, conferido pelo lugar de crítica conquistado por nós na tradição milenar representada pela universidade.

Apesar de proposto no PDI vigente em 2010 a Escola de Extensão até agora não sofreu nenhuma iniciativa senão grafado como intenção "promover a socialização de conhecimentos produzidos e acumulados na academia 3.1 implantar e fortalecer a Escola de Extensão da UFPA" (PLANO DE DESENVOLVIMENTO DA UNIVERSIDADE FEDERAL DO PARÁ 2001-2010, p. 81).

A UFPA deve pautar expressamente a configuração de proposta político acadêmica da escola a exemplo das já existentes como UNB e UNICAMP, de modo a executar uma política agressiva de expansão da oferta de tecnologias e serviços para serem absorvidos na geração de renda, na catalogação das necessidades do mercado de trabalho, bem como no estimulo a organização associativa solidaria e cooperativa.

$\mathrm{Na}$ área cultural os desafios são volumosos, a noção de arte e cultura como apêndice da missão institucional provoca uma série de equívocos cujo mais grave é a percepção desta área de saber como subproduto da elaboração cientifica, portanto sujeito ao improviso no financiamento, planejamento e execução. A falta de exigência de uma cultura organizativa acaba por redundar no aprofundamento do caráter de espetacularização da cultura desconectando do caráter de pesquisa e experimentação tão caro à discussão dos foros de arte. 
Extensão do saber numa universidade amazônica

A relevância de editar intervenções continuadas como representa o Encontro de Arte de Belém (ENARTE) permitiu-nos conferir a programação para o entorno do campus de Belém, tanto quanto sua circulação nos campi do interior; o exercício de feição multicampi em construção, disponibilizando a integração entre ensino, pesquisa e extensão ao associar-se ao esforço local de ampliar a oferta de arte e do repertorio cultural existente na universidade articula a sinergia da produção cultural; esta compreensão tem orientado a legitimação da profissionalização da produção cultural via a oferta continuada ao longo do ano de Oficinas de Elaboração de Projetos Culturais, e, de modo recorrente no Plano Acadêmico-Institucional.

Ser o outro do ensino e pesquisa não atende a importância da universidade em suas relações com a sociedade senão assegurar a sinapse que propicie a produção de saber informada pela diversidade, pela necessidade continua de ampliação de conhecimento da realidade social na qual a instituição se insere; particularmente quanto à ecologia da Amazônia e as demandas sociais às quais reclamam respostas cujo fim é razão de ser da instituição.

Somente quando a universidade submete à sociedade o saber produzido esta ratifica sua missão. Isto posto, a síntese indissociável entre o ensino, pesquisa e a extensão permite a renovação do pacto de sustentabilidade político-financeira quando solidifica a perspectiva de agregação de valor material e simbólico ao projeto de desenvolvimento local, nacional e universal. Essa característica não estava inscrita na origem da universidade, essa exigência nos foi colocada no presente. Um projeto de ação inclui um projeto de universidade. Ao vivenciarmos a mundialização, deparamo-nos com a velocidade de transformações em escala criando e/ou aprofundando dramas como a violência, a competição desenfreada depredando a natureza, o homem e a cultura. A falência do socialismo real não produziu a era de ouro do capitalismo, ao contrário estimulou maior concentração de riqueza, entrementes vivenciemos a plenitude o sistema produtor de mercadorias, vagas de libertação forjaram condições para requerer a descoberta da cidadania como parte constitutiva da humanização. 
Extensão do saber numa universidade amazônica

A universidade pública não pode prescindir do trato com o projeto de humanidade. Nos últimos tempos a universidade desdobra-se para conquistar mais capital com a pesquisa criando um perigoso fosso entre esta e suas outras faces, ensino e extensão; contudo o limite já ficou patente, com a formação debilitada na graduação, muito pouco a faceta pesquisa pode lograr; vexatória tornar-se a situação quando as tecnologias geradas no seu interior não encontram meios de serem acolhidas, portanto, é imperioso construir um plano de extensão que ultrapasse as veleidades individuais ou das vocações e intensifique a sinapse da realidade com a universidade e esta última ofereça à formação discente a integração entre ensino, pesquisa e extensão.

Neste percurso devemos elaborar outras metodologias para comunicar estes saberes. Não basta desenvolver tecnologias de ponta se aqueles a manipularem seu conteúdo e forma não tiverem apreendido a utilizar estas ferramentas, sob o manto da inovação não se pode dispensar a capacidade de utilização dessas tecnologias além dos quadros para qual foram constituídas originalmente. Há variáveis que devidamente estimuladas podem gerar saltos na produção de conhecimento.

\section{CONSIDERAÇÕES FINAIS}

A universidade não é apenas o lócus físico do pensar como projetado até então, ela foi esfumaçada no ar para gozar sua capacidade de revolucionar a si e seu entorno. Observa-se esta disposição quando encontramos o desenvolvimento de projetos acadêmicos circunscrevendo um problema ao invés da memorização e do conteúdo disciplinar; a este exemplo temos a música, não basta ao músico a teoria musical à formação, esta deve ser temperada pelo quotidiano insistente com suas vibrações sensoriais e sensuais, tanto quanto a física encontra vitalidade no princípio de incerteza de Heisemberg; para discorrer em história basta percebemos como um nazista viu a queda o reich, enquanto o comunista exultou.

Essas cenas fáticas visam obter uma adesão à mudança em seu caráter ao trasladar a condição de reflexão-ação para condição de práxis. Os dados agrupados em categorias e temporalmente nos anos de 2008-9 serviram para ilustrar os microcosmos o que fizemos, mas principalmente o que não contabilizamos e que devemos fixar os desafios da extensão na UFPA neste milênio. Talvez Santos $(2005$, p.114) tenha mesmo razão quando afirma que “enquanto bem público [a Universidade] reside em ser ela a instituição que liga o presente ao médio e longo prazo pelos conhecimentos e pela formação que produz e pelo espaço público 
Extensão do saber numa universidade amazônica

privilegiado de discussão aberta e crítica que constitui”.

\section{REFERÊNCIAS}

BRASIL. Governo Federal. Decreto 6.096, de 25.04.2007, que institui o Programa de Reestruturação e Expansão das Universidades Federais - REUNI.

COELHO, M. S. C.; DIAS, Ana Lucia B; SANTOS, Fábio A S. A Política de Interiorização da Universidade Federal do Pará no município de Cametá-PA. Olhar de Professor (UEPG), Ponta Grossa- Paraná, p. 35-47, 2004.

HAESBAERT, R. O mito da desterritorialização: do "fim dos territórios" à multiterritorialidade. Rio de Janeiro: Editora Bertrand Brasil, 2004, 395 p.

SANTOS, B. S. A Universidade no Século XXI: para uma reforma democrática e emancipatória da Universidade. $2^{\mathrm{a}}$ Ed. São Paulo: Editora Cortez, 2005. (Coleção questões de nossa época; v. 120), 120 p.

UNIVERSIDADE FEDERAL DO PÁRÁ. Pró-Reitoria de Planejamento e Desenvolvimento. Plano de Desenvolvimento da Universidade Federal do Pará: 2001-2010. Belém, EDUFPA, 2003, 180 p. 